\title{
The Effect of Seed Crystals of Hydroxyapatite and Brushite on the Crystallization of Calcium Oxalate in Undiluted Human Urine In Vitro: Implications for Urinary Stone Pathogenesis
}

\author{
Phulwinder K. Grover, ${ }^{1}$ Dong-Sun Kim, ${ }^{1,2}$ and Rosemary Lyons Ryall ${ }^{1}$ \\ ${ }^{1}$ Department of Surgery, Flinders University School of Medicine, Flinders Medical Centre, Bedford Park, \\ South Australia \\ ${ }^{2}$ Present address: Department of Urology, Korea University Guro Hospital \#80, Guro-Dong, Guro-Gu, \\ Seoul, Korea
}

Accepted March 25, 2002

\begin{abstract}
Background: The aim of this study was to determine whether crystals of hydroxyapatite (HA) or brushite (BR) formed in urine promote the epitaxial deposition of calcium oxalate $(\mathrm{CaOx})$ from undiluted human urine in vitro and thereby explain the occurrence of phosphate in the core of urinary stones consisting predominantly of $\mathrm{CaOx}$. Materials and Methods: Crystals of HA, BR, and CaOx were generated from human urine and their identity confirmed by X-ray analysis. Standard quantities of each crystal were then added to separate aliquots of pooled undiluted human urine and $\mathrm{CaOx}$ crystallization was induced by the addition of identical loads of sodium oxalate. Crystallization was monitored by Coulter Counter and ${ }^{14} \mathrm{C}$-oxalate analysis and the precipitated crystals were examined by scanning electron microscopy.

Results: In comparison with the control to which no seeds were added, addition of $\mathrm{CaOx}$ crystals increased the deposition of ${ }^{14} \mathrm{C}$-oxalate by $23 \%$. On the other hand, seeds of HA and BR had no effect. These findings
\end{abstract}

were supported by Coulter Counter analysis, which showed that the average modal sizes of crystal particles precipitated in the presence of $\mathrm{HA}$ and BR seeds were indistinguishable from those in the control, whereas those deposited in the presence of $\mathrm{CaOx}$ were significantly larger. Scanning electron microscopy confirmed these results, demonstrating that large aggregates of $\mathrm{CaOx}$ dihydrates were formed in the presence of $\mathrm{CaOx}$ seeds, whereas BR and to a lesser extent HA seeds were scattered free on the filtration membrane and attached like barnacles on the surface of the freshly precipitated CaOx crystals.

Conclusion: Seed crystals of HA or BR do not promote $\mathrm{CaOx}$ deposition in urine in vitro and are therefore unlikely to influence $\mathrm{CaOx}$ crystal formation under physiologic conditions. However, binding of HA and BR crystals to, and their subsequent enclosure within, actively growing $\mathrm{CaOx}$ crystals might occur in vivo, thereby explaining the occurrence of mixed oxalate/phosphate stones.

\section{Introduction}

Urinary stone formation is a serious, debilitating problem in all societies throughout the world. It is estimated that approximately $12 \%$ of the population will suffer from the disease at some stage in their lives (1) and that men are three times more prone to the disease than are women $(2,3)$. More recent studies suggest that there has been a gradual increase in the annual incidence and a decrease in the age of onset of the disease-perhaps the result of change in lifestyle and diet (4). It is therefore not surprising that financial costs of the disease are staggering; in the United States, for instance, the health bill for treatment of kidney stones runs to billions of dollars annually (5). Therefore studies investigating why, or more importantly, how stones form are of utmost importance for prevention, early intervention, better

Address correspondence and reprint requests to: Dr. Phulwinder K. Grover, Department of Surgery, Flinders Medical Centre, Bedford Park, South Australia 5042, Australia. Phone: 618204 4489; fax: 618374 0832; e-mail: pk.Grover@flinders.edu.au. patient care, and reducing the financial burden of the disease.

All urinary stones consist of an inorganic moiety; the majority are made up of calcium oxalate $(\mathrm{CaOx})$ and a mixture of several crystalline mineral phases $(6,7)$. In urinary calculi containing more than one mineral, the inorganic fraction is arranged in concentric layers of abruptly differing composition around a common nucleus $(6,8)$. One interesting feature of such stones is that their centre usually consists of different forms of calcium phosphate (CaP). These include hydroxyapatite (HA), $\left.\mathrm{Ca}_{10}\left(\mathrm{PO}_{4}\right)_{6}(\mathrm{OH})_{2}\right)$, also known as basic calcium hydrogen phosphate, and rarely, brushite (BR), CaHPO ${ }_{4} \cdot 2 \mathrm{H}_{2} \mathrm{O}$, otherwise known as calcium hydrogen phosphate dihydrate (6-7,9-10). In an attempt to explain the formation of urinary stones consisting of mixed layers of different minerals, Modlin (8) invoked the phenomenon of epitaxy, a process involving oriented overgrowth of one crystalline phase upon another and requiring a near geometrical fit between the respective networks that are in contact (11). Later, using X-ray crystallography, 
Lonsdale (12) demonstrated the existence of several crystal lattice fits for many crystal phases of minerals commonly present in urinary calculi. Based on these findings, which at least supported the theoretical possibility of epitaxial growth of $\mathrm{CaOx}$ on different minerals, including $\mathrm{HA}$ and $\mathrm{BR}$, she proposed the process of epitaxy both as a mechanism of stone formation, and to explain the encapsulation of a crystal core by alternating layers of other minerals, a pattern commonly seen in urinary calculi $(12,13)$. These findings for the first time raised the possibility of epitaxial growth of $\mathrm{CaOx}$ onto HA or BR crystals as one possible mechanism of stone formation.

A prerequisite for the epitaxial deposition of $\mathrm{CaOx}$ onto a $\mathrm{CaP}$ nidus is that the urine be supersaturated with both $\mathrm{CaOx}$ and $\mathrm{CaP}$. This requirement is fulfilled; several studies have revealed that although the urine of normals and stone-formers is often supersaturated with $\mathrm{CaOx}(10,14-17)$ and hydroxyapatite $(18,19)$, that of stone patients is supersaturated with BR as well $(10,14-17)$. The results of these physicochemical studies are supported by the observations that crystals of $\mathrm{CaOx}$ and $\mathrm{CaP}$ are more common in the urine of stone-formers than in that from healthy subjects $(18,19)$. Furthermore, long-term follow-up studies of patients after extracorporeal shockwave lithotripsy showed that the stone recurrence rate was higher in patients with a history of frequent formation of stones with a high content of CaP (20). Some researchers have even suggested that the CaP content of renal stones is a useful factor in predicting the future course of the disease (21). On the basis of these observations, the overall weight of evidence supports the possibility that $\mathrm{CaP}$ particles in the urine of stone-formers initiate $\mathrm{CaOx}$ stone genesis by acting as seeds for heterogeneous deposition. Experimental verification that epitaxial deposition of $\mathrm{CaOx}$ on CaP can occur was obtained when Pak et al. $(22)$ and Meyer et al. $(23,24)$ reported that HA and BR crystals enhanced the precipitation of $\mathrm{CaOx}$ from an inorganic metastable solution. These observations were later confirmed by other investigators (25-33) and subsequently cited by innumerable authors as corroborative evidence for the probability that epitaxy plays a major role in the formation of mixed calcium stones. However, although the data proved conclusively that epitaxial deposition of $\mathrm{CaOx}$ on HA and BR can occur under inorganic conditions, they are largely academic from a pathophysiologic perspective, because stones are formed in urine, which, in addition to common inorganic constituents, also contains a wide selection of organic macromolecules whose possible effects on the process have never been studied. Moreover, it is also known that crystals of CaP precipitated from human urine contain a number of macromolecules $(34,35)$ whose presence will undoubtedly affect the geometrical lattice fit between the contacting mineral surfaces. Therefore, if an epitaxial relationship exists between $\mathrm{CaOx}$ and $\mathrm{CaP}$ salts in urine, it is more likely to be dictated by the macromolecular coat of the crystals than by the lattice characteristics of the pure mineral phases.

The aim of the present investigation was to determine, using Coulter Counter and radioactive oxalate analysis, and scanning electron microscopy, whether crystals of HA and BR formed in human urine can induce the epitaxial deposition of $\mathrm{CaOx}$ from undiluted human urine and thereby explain the common observation of a $\mathrm{CaP}$ core within stones consisting predominantly of $\mathrm{CaOx}$. Crystals of $\mathrm{CaOx}$ derived from the same urine were also included as a basis for comparison.

\section{Materials and Methods}

Preparation of Seed Crystals of $\mathrm{HA}, \mathrm{BR}$, and $\mathrm{CaOx}$

Collection and Preparation of Urine Samples Twentyfour-hour urine specimens were collected without preservative from 10 healthy men who had no previous history of urinary stone disease. The samples were refrigerated during the collection period and during storage before use. After confirming the absence of blood from each urine sample by dip stick analysis (Combur Test, Roche Diagnostics, Mannheim, Germany), they were pooled and centrifuged at $8000 \times \mathrm{g}$ for $15 \mathrm{~min}$ at $20^{\circ} \mathrm{C}$ in a Beckman J2-21M/E centrifuge (Beckman Instruments, Palo Alto, CA, USA) using a JA-14 fixed-angle rotor. The supernatant was filtered through $0.22-\mu \mathrm{m}$ Millipore filters (\#GVWP 142 50, Millipore Corporation, Bedford, MA, USA) and divided into three portions for preparation of $\mathrm{HA}, \mathrm{BR}$, and $\mathrm{CaOx}$ crystals.

Generation of HA Seed Crystals A solution of calcium chloride ( $1 \mathrm{~mol} / \mathrm{l})$ was added dropwise to the urine at $37^{\circ} \mathrm{C}$ to give a final concentration of $\sim 20 \mathrm{mmol} / \mathrm{l}$. The $\mathrm{pH}$ of the urine was adjusted to 7.5 with $1 \mathrm{~mol} / \mathrm{l} \mathrm{NaOH}$ and the sample was incubated in a shaking water bath at $37^{\circ} \mathrm{C}$ for a further $6 \mathrm{hr}$. The precipitated crystals were harvested by filtration through $0.22-\mu \mathrm{m}$ Millipore filters and washed thoroughly with distilled water. They were then freeze-dried and stored at $-20^{\circ} \mathrm{C}$ until required.

Generation of BR Seed Crystals Under the same conditions used to prepare the HA crystals, a solution of $\mathrm{KH}_{2} \mathrm{PO}_{4}(1 \mathrm{~mol} / \mathrm{l})$ was added dropwise to the second portion of the urine sample to give a final concentration of $\sim 80 \mathrm{mmol} / \mathrm{l}$. The urine $\mathrm{pH}$ was then adjusted to 6.0 with $1 \mathrm{~mol} / \mathrm{l} \mathrm{HCl}$ and the sample incubated in a shaking water bath at $37^{\circ} \mathrm{C}$ for $6 \mathrm{hr}$. The precipitated crystals were harvested, washed, freeze dried, and stored as described above.

Generation of CaOx Seed Crystals CaOx seed crystals were precipitated from the third portion of the urine as described previously (36). Briefly, the empirical metastable limit of the pooled urine with respect to $\mathrm{CaOx}$ was determined using a Model TAII 
Coulter Counter fitted with a Population Count Accessory (Coulter Electronics Ltd, Herts, United Kingdom) following titration with sodium oxalate solution. A standard load of oxalate was added dropwise to the urine sample, which was then incubated in a shaking water bath at $37^{\circ} \mathrm{C}$. The same amount of sodium oxalate solution was added after $\mathrm{l}$ and $2 \mathrm{hr}$ and the urine was incubated for a further $4 \mathrm{hr}$. The crystals were harvested, washed, freezedried, and stored as described.

$X$-Ray Powder Diffraction The identities of the precipitated HA, BR, and CaOx seed crystals were confirmed by X-ray analysis. The crystals were ground thoroughly and their X-ray diffraction patterns were recorded with a Phillips PW 1710 microprocessorcontrolled diffractometer using cobalt radiation, a variable divergence slit, and a graphite monochromator. The diffraction patterns were recorded in steps of 0.05 with a 1-sec count time per step. The patterns were logged to permanent data files on an IBM/XT computer (37) and subsequently analyzed using a software package developed by Raven and Self (38). Standard HA and CaOx were purchased from Sigma Chemical Company (St. Louis, MO, USA) and brushite was kindly provided by Professor C.Y.C. Pak (University of Texas Southwestern Medical Center at Dallas, Dallas, Texas, USA)

\section{Crystallization Experiments}

Measurement of Crystallization by Coulter Counter Analysis Although the use of whole urine would obviously have been ideal, it cannot be used for experiments using Coulter Counter analysis because of high background particle counts resulting from cellular debris and polymerized Tamm-Horsfall glycoprotein (THG). The removal of THG and some human serum albumin (HSA) by centrifugation and filtration (39) is unlikely to affect the crystallization of $\mathrm{CaOx}$ under the conditions used here because neither THG nor HSA has any significant effect on $\mathrm{CaOx}$ crystal growth in undiluted human urine (40). Therefore, urine that had been centrifuged and filtered was used in the following experiments.

Additional 24-hr urine samples were collected from healthy men. After confirming the absence of hematuria, they were pooled, centrifuged, and filtered, and the metastable limit with respect to $\mathrm{CaOx}$ determined as described. One-quarter of the urine was retained as control, and the remainder was divided into three aliquots. Seed crystals of $\mathrm{HA}, \mathrm{BR}$, and $\mathrm{CaOx}$ prepared as described were gently ground in an agate mortar to remove large lumps so they could be counted accurately by the Coulter Counter, and slurries containing $2 \mathrm{mg} / \mathrm{ml}$ of each seed type were prepared in $0.15 \mathrm{~mol} / \mathrm{l} \mathrm{NaCl}$ solution and mixed overnight in a rotary mixer. It is remarkable that grinding of the seed crystals does not affect their molecular lattice and thus is highly unlikely to affect their ability to induce crystallization of CaOx. Identical volumes were then added to aliquots of the urine to give a final suspension concentration of $2 \mathrm{mg} / 100 \mathrm{ml}$ urine; the control sample was treated with an equivalent volume of $0.15 \mathrm{~mol} / \mathrm{l} \mathrm{NaCl}$ solution. This value of seed suspension concentration was chosen to minimize coincidence while counting particles using the Coulter Counter. The volume size distributions of each seed crystal suspension were determined by Coulter Counter analysis. Crystallization of $\mathrm{CaOx}$ was then induced in the samples by the dropwise addition of sodium oxalate solution to increase the concentration by $15 \mu \mathrm{mol} / 100 \mathrm{ml}$ in excess of the measured metastable limit. The samples were incubated for 120 min in a shaking water bath at $37^{\circ} \mathrm{C}$, and the particle size distributions were determined at $15-\mathrm{min}$ intervals using the Coulter Counter. Preliminary experiments revealed that the intra-assay and inter-assay coefficients of variation of determination of modal particle size were $6.1 \%$ and $8.9 \%$, respectively. Each experiment was performed in sextuplicate. These samples will be referred to as "cold."

Measurement of Mineral Deposition by ${ }^{14} \mathrm{C}$-Oxalate The use of the Coulter Counter to determine crystal growth has a number of limitations: a) if the crystals are loosely aggregated, the empty spaces between them are counted as if they are solid material, thereby giving an erroneously high estimate of crystal volume; b) because the Coulter Counter measures particle size within specified limits (in these experiments, 2-25.4 $\mu \mathrm{m}$ ), crystals falling outside this range will not be recorded; and c) the Coulter Counter cannot account for differences in particle density. Therefore, to estimate the true mass of $\mathrm{CaOx}$ deposited, parallel incubations were carried out with samples containing ${ }^{14} \mathrm{C}$-oxalate $(2.5 \mu \mathrm{Ci} / 100 \mathrm{ml}$ urine), in which any alterations in radioactivity must reflect corresponding changes in $\mathrm{CaOx}$ precipitation. Radioactive urines were treated identically to those described above, except that the samples were supplemented with ${ }^{14} \mathrm{C}$-oxalic acid (NEN Products, Boston, MA, USA) before the oxalate load was added to induce $\mathrm{CaOx}$ crystallization. At intervals of $15 \mathrm{~min}, 2.5 \mathrm{ml}$ of each sample was filtered $(0.22 \mu \mathrm{m})$ into $200 \mu \mathrm{l}$ of concentrated $\mathrm{HCl}$ using disposable syringes fitted with filters (Sartorius Minisart NML, Gottingen, Germany). Duplicate 1-ml aliquots of these solutions were then added to $10 \mathrm{ml}$ of Ready Safe scintillation fluid (Beckman Instruments Inc) and counted for $2 \mathrm{~min}$ in a liquid scintillation counter (Beckman LS 3801 Liquid Scintillation System). Preliminary experiments revealed that the intra- and inter-assay coefficients of variation of measurement of CaOx deposition by ${ }^{14} \mathrm{C}$-oxalate analysis were $3.9 \%$ and $5.1 \%$, respectively. Each experiment was performed in sextuplicate. These samples will be referred to as "hot." 
Scanning Electron Microscopy At the end of each experiment, 1-ml aliquots of each cold sample were filtered $(0.22 \mu \mathrm{m})$ and the filtration membrane dried overnight at $37^{\circ} \mathrm{C}$. Each membrane was then mounted on an aluminum stub and coated with gold for 180 sec using an SEM Autocoating Unit E5200, (Polaron Equipment Ltd, Watford, United Kingdom). The stubs were examined using an ETEC Auto Scan Electron Microscope (Siemens AG, Karlsruhe, Germany) at an operating voltage of $20 \mathrm{kV}$.

\section{Statistical Methods}

For the sake of clarity, data are plotted as mean values: nonetheless, statistical comparisons were performed using the Wilcoxon signed rank sum test at an 0.05 level of significance.

\section{Results}

\section{Sizes of Seed Crystals}

Figure 1 shows the volume distribution of the seeds at zero time (before addition of the oxalate load). It can be seen that the particle size distributions of the three seed types were very similar. The average modal size in all cases was approximately $6.35 \mu \mathrm{m}$, and the average total particle volumes of each suspension were also alike: 3692,3716 , and $4089 \mu \mathrm{m}^{3} / \mu \mathrm{l}$ for HA, BR, and $\mathrm{CaOx}$ seeds, respectively. Although it is apparent from the shape of the distribution curves that a small percentage of the $\mathrm{CaOx}$ seed crystals, and slightly more of the BR and HA seeds, lay below the detection limit of the Coulter Counter, which in these experiments was $2 \mu \mathrm{m}$, it is apparent that, for all practical purposes, the Coulter Counter volume distribution curves for each type of seed provide an adequate quantitative estimation of average modal particle size. Furthermore, the close similarity between the initial modal sizes obviates the need to

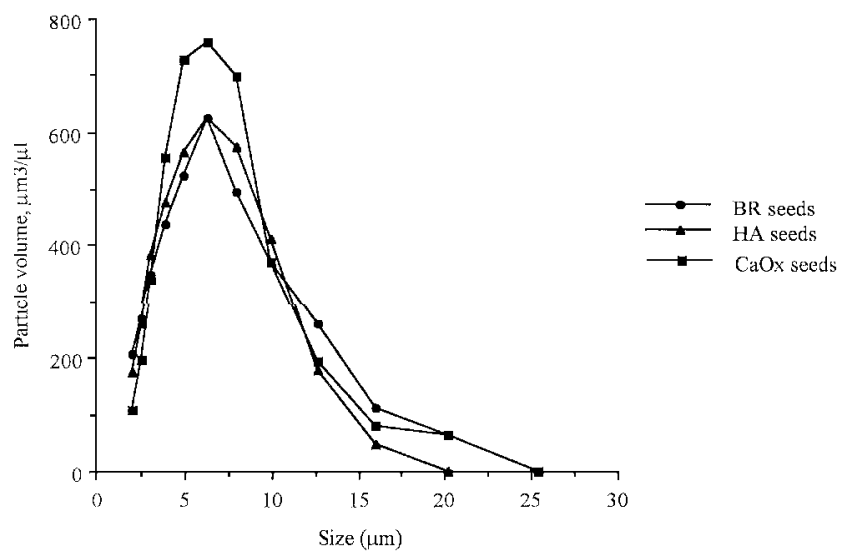

Fig. 1. Particle size distributions of seeds of hydroxyapatite (HA), brushite (BR), and calcium oxalate ( $\mathrm{CaOx})$. The average modal sizes of each seed suspension were alike and were within the Coulter Counter-specified limits (in these experiments, $2-25.4 \mu \mathrm{m})$. correct values obtained after the 2-hr incubation period for those at zero time.

\section{Effect of Seed Crystal Composition on Particle Size}

Figure 2 shows the volume distribution of the particles at the end of the incubation period, in the control and in the presence of the various types of seed crystals. After $2 \mathrm{hr}$, the average modal size of the particles deposited in the presence of seed crystals of $\mathrm{CaOx}, \mathrm{HA}$, and BR were 16.8, 11.8, and $11.9 \mu \mathrm{m}$, respectively, in comparison with the control (containing no added seeds) value of $11.7 \mu \mathrm{m}$. These represent corresponding increases in particle size, relative to the control, of 43.6 ( $p \leq 0.05$ ), 0.9 (nonsignificant), and $1.7 \%$ (nonsignificant), respectively. These findings are confirmed in the scanning electron micrographs presented in Figures 3 and 4.

Figure 3 shows low power scanning electron micrographs of the particles deposited in the absence of seeds, and in the presence of crystalline $\mathrm{CaOx}$ and HA and BR. The crystalline particles precipitated from the control sample consist principally of small $\mathrm{CaOx}$ dihydrate crystals, which were single or clustered into small aggregates of several crystals. In contrast, individual crystals precipitated in the presence of $\mathrm{CaOx}$ seeds were large $(>10 \mu \mathrm{m})$ and highly aggregated into structures of 50-60 $\mu \mathrm{m}$. Crystalline particles deposited in the presence of BR, and to a lesser extent HA seeds, although tending to be grouped into clumps, were nonetheless small in comparison to those precipitated in the presence of $\mathrm{CaOx}$ seeds. Seed crystals of HA and BR were clearly seen scattered across the filtration membranes. Higher power micrographs of the crystalline particles are presented in Figure 4.

At higher magnification, the crystalline particles deposited showed protuberances, apparently caused

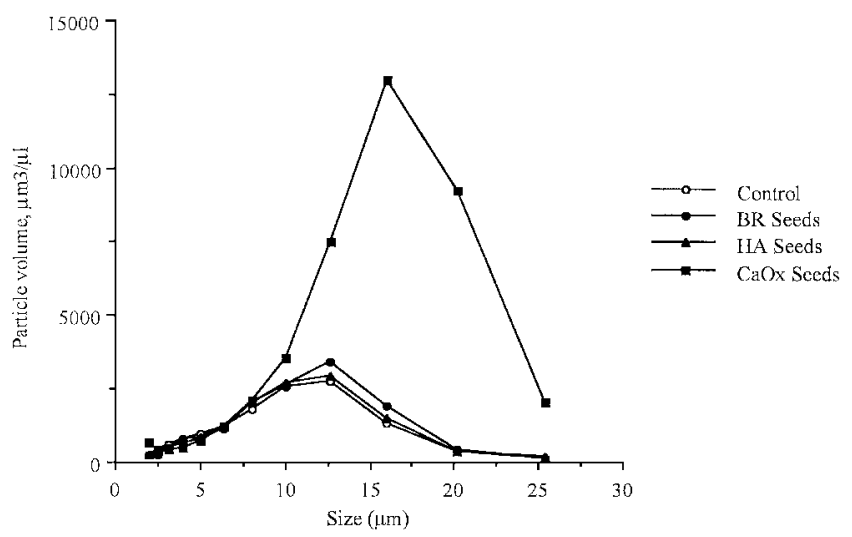

Fig. 2. Particle size distribution at $2 \mathrm{hr}$ after the addition of oxalate load, in the control urine (no seeds) and samples of the same urine containing seeds of HA, BR, and CaOx. The values represent that although the addition of HA and BR seeds did not significantly affect the average modal size of the precipitated particles, CaOx seeds increased it by $43 \%$ $(p \leq 0.05)$ in comparison with the control sample to which no seed crystals were added. 


\section{The effect of seed type on calcium oxalate crystallization}

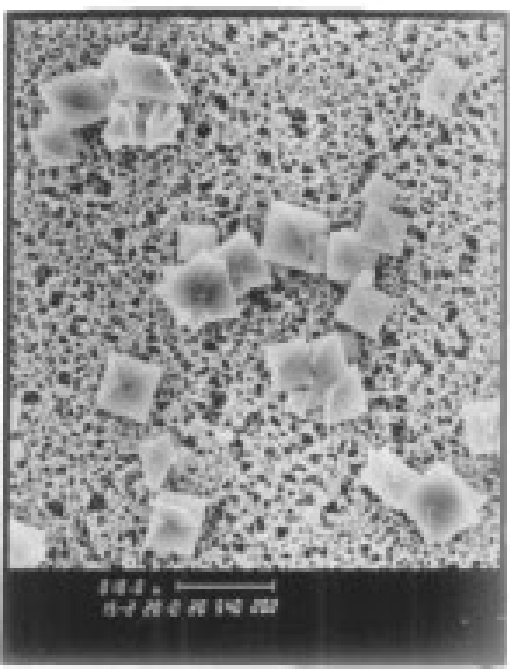

No Seeds

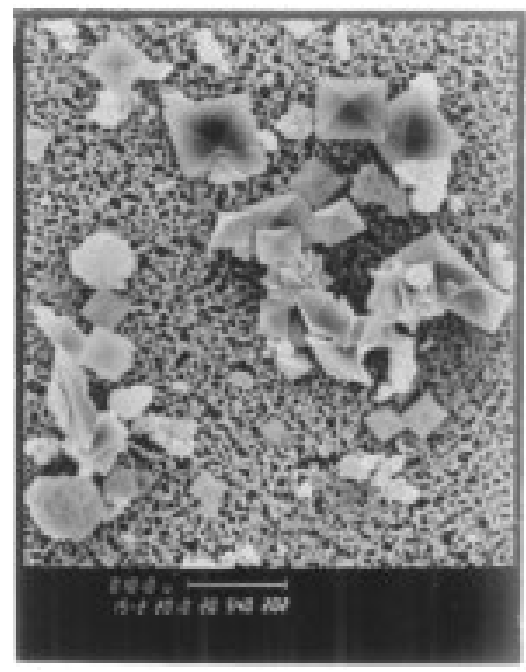

Hydroxyapatite

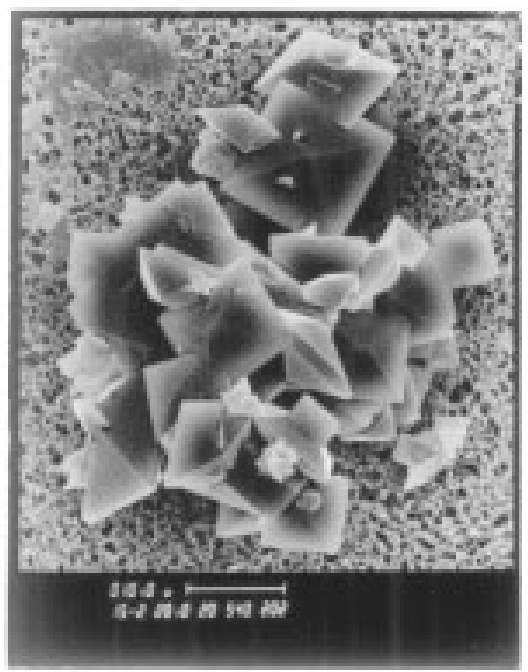

Calcium Oxalate

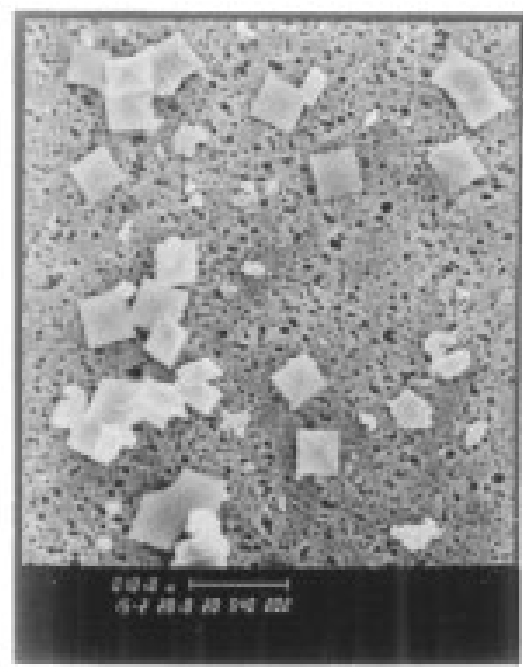

Brushite
Fig. 3. Low power scanning electron micrographs of the crystalline materials deposited in the absence and presence of seeds of HA, BR, and CaOx. Note the presence of HA and BR seeds scattered on the membrane and on the CaOx crystal surfaces. by engulfment of small, freshly nucleated $\mathrm{CaOx}$ crystals and the seed crystals by the $\mathrm{CaOx}$ growth front. In the presence of HA and BR seeds, however, the seeds are also seen lying free on the filtration membrane and attached like barnacles on the surfaces of the freshly precipitated $\mathrm{CaOx}$ crystals.

\section{Assessment of Crystal Deposition by ${ }^{14} \mathrm{C}$-Oxalate Analysis}

Figure 5 shows the time course of disappearance of ${ }^{14} \mathrm{C}$-oxalate from the supernatants of the urine samples throughout the incubation period after addition of the oxalate load. To normalize the data, the values are presented as the amount of ${ }^{14} \mathrm{C}$-oxalate remaining in the solution, expressed as a percentage of the zero time value. Two features of these data are remarkable. First, as expected, values recorded in the samples containing $\mathrm{CaOx}$ seeds differed dramatically from those observed in the presence of $\mathrm{HA}$ and $\mathrm{BR}$ seeds. Second, the rate of reduction in ${ }^{14} \mathrm{C}$-oxalate in the control sample (containing no added seeds) was almost indistinguishable from those supplemented with seed crystals of HA or BR. At $2 \mathrm{hr}$, the mean percentage reduction in ${ }^{14} \mathrm{C}$-oxalate in the control urine containing no seed crystals $(79.2 \%)$ was very close to the values obtained in the presence of seed crystals of HA $(78.9 \%)$ and BR $(77.7 \%)$. However, it was in the presence of $\mathrm{CaOx}$ seeds that the most dramatic reduction in ${ }^{14} \mathrm{C}$-oxalate occurred, with the value at $2 \mathrm{hr}$ being only $60.8 \%$. These values demonstrate that seed crystals of $\mathrm{HA}, \mathrm{BR}$, and $\mathrm{CaOx}$ 
The effect of seed type on calcium oxalate crystallization

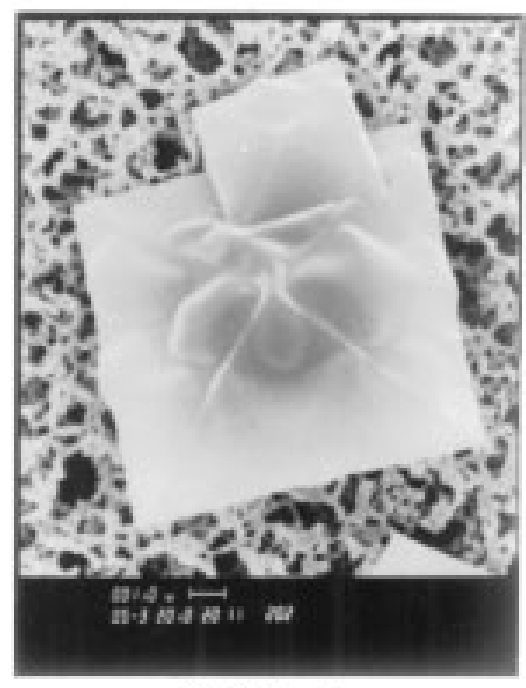

No Seeds

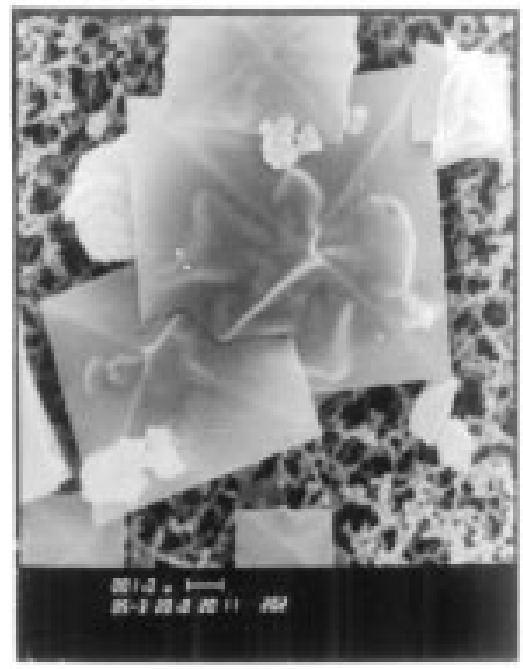

Hydroxyapatite

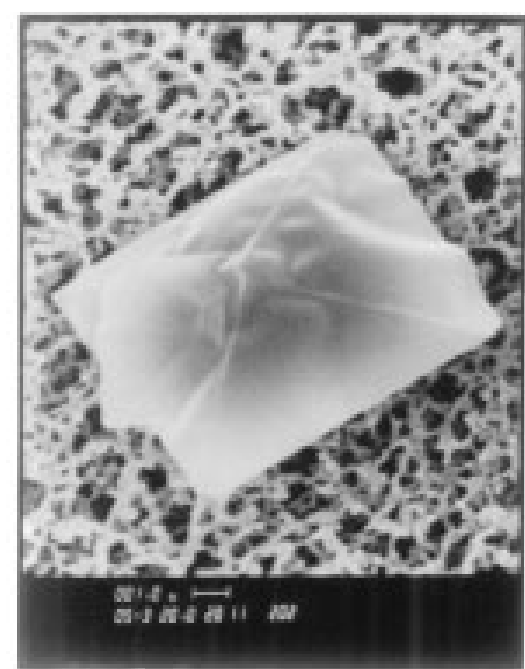

Calcium Oxalate

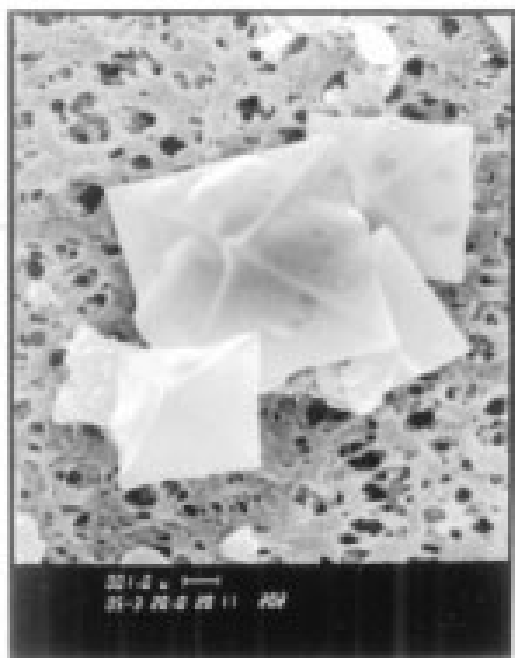

Brushite
Fig. 4. High power scanning electron micrographs of the samples shown in Fig. 3. Note that the crystalline particles deposited show protuberances, apparently caused by engulfment of small, freshly nucleated CaOx crystals and the seed crystals by the $\mathrm{CaOx}$ growth front. In the presence of HA and BR seeds, however, the seeds are also seen lying free on the filtration membrane and attached like barnacles on the surfaces of the freshly precipitated CaOx crystals. increased the mineral deposition by 0.37 (nonsignificant), 1.82 (nonsignificant), and $23.23 \%(p \leq 0.05)$, respectively, in relation to the control to which no seed crystals were added.

\section{Discussion}

A number of theories have been proposed in an attempt to explain the formation of urinary calculi. Of these, epitaxy has been the most often cited, its credibility having been reinforced by the presence of alternating layers of different minerals around a CaP core (6-10). The fact that human urine only occasionally attains levels sufficient to allow the spontaneous nucleation of $\mathrm{CaOx}$ crystals (41), and the existence of geometrical fits between the crystalline lattice dimensions of $\mathrm{CaOx}$ and that several crystalline phases of minerals commonly present in urinary calculi $(12,28,31)$, have strengthened the supposition.

Human urine is commonly supersaturated with respect to $\mathrm{CaOx}$ and brushite $(10,14-17)$, especially in patients with high concentrations of urinary calcium and/or phosphate and alkaline urinary pH (42). This favors the formation of CaP particles that could, at least theoretically, act as nidi for the deposition of $\mathrm{CaOx}$. It is noteworthy that the solubility of CaP decreases with increasing $\mathrm{pH}$. Typically, CaP precipitates when the urine $\mathrm{pH}$ is higher than 6.2 (43); BR generally forms in mildly acidic urine, and HA forms in alkaline urine $(44,45)$. Although $\mathrm{HA}$ is the most common crystal in urine from both normal and 


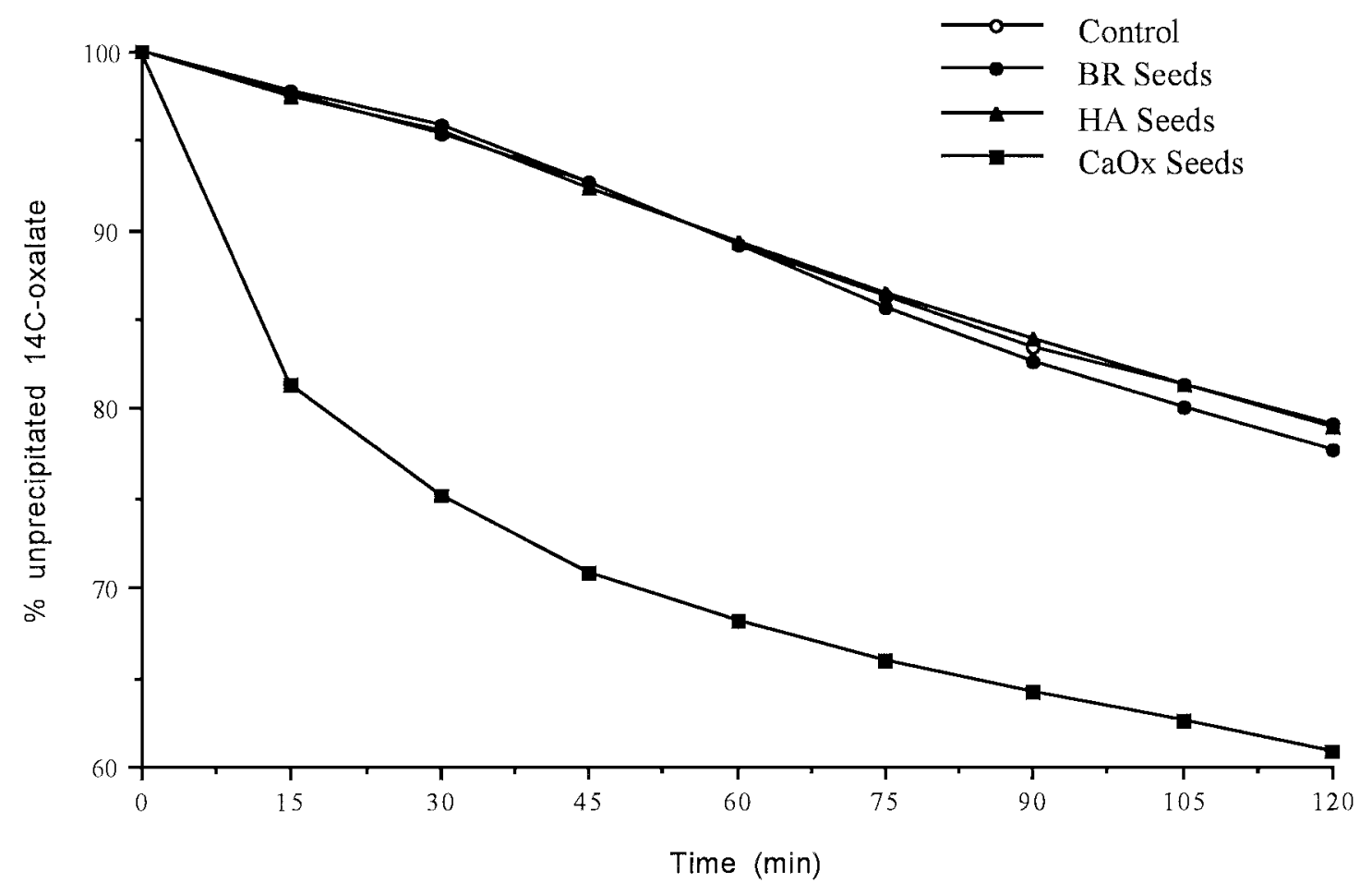

Fig. 5. Change in unprecipitated ${ }^{14} \mathrm{C}$-oxalate following the addition of the oxalate load in the control urine to which no seeds were added and samples of the same urine containing seeds of HA, BR, and CaOx. The values obtained represent that although seed crystals of $\mathrm{CaOx}$ promoted the mineral deposition by $23 \%(p \leq 0.05)$, HA and BR seeds had no significant effect in comparison with the control, to which no seeds were added.

stone-forming subjects $(18,19)$, BR rarely presents as crystalluria and is only seen in urine from patients with hyperparathyroidism or idiopathic CaOx urolithiasis (46), which might also explain why BR is infrequently found in urinary calculi $(6-7,9-10)$. It has been suggested that although BR is the initial CaP phase precipitated in urine (45), it subsequently transforms into HA in response to excretion of alkaline urine, which is not uncommon at certain times of the day and during the course of stone disease (47). BR is not stable above a pH of $6.9(44,45)$; in alkaline urine it preferentially takes up calcium and transforms into HA, which is the thermodynamically stable phase of CaP in alkaline urine (48).

Although studies have shown that crystalline particles of $\mathrm{HA}$ and BR can induce precipitation of $\mathrm{CaOx}$ from metastable inorganic solutions $(22,33)$, similar results have never been obtained in urine. Because the physicochemical properties of urine bear scant similarity to those of inorganic solutions, this cautions against extrapolating findings from inorganic solutions to predict likely effects in whole urine, particularly on stone formation. Perhaps the most compelling reason for exercising caution is that the latter contains large numbers and quantities of low- and high-molecular-weight components, some of which are well-documented inhibitors of $\mathrm{CaOx}$ crystallization (49). Furthermore, the concentrations and relative amounts of various urinary constituents differ from one urine specimen to another. Thus it is fair to say that the effects of all urinary components on the epitaxial relationship between $\mathrm{CaOx}$ and $\mathrm{HA}$ or BR cannot possibly be reproduced under experimental conditions using inorganic salt solutions in vitro.

The separate effects of citrate $(26,29)$, magnesium (29), osteopontin (OPN), THG, chondroitin sulphate (CS), a fraction of urinary macromolecules (UM) (33), and HSA $(29,33)$ on the HA-induced deposition of $\mathrm{CaOx}$ under inorganic reaction conditions have been previously investigated. Generally, these substances increased the induction time, except CS, which decreased it (33). HSA was reported to promote nucleation in one case (29), but inhibit it in another (33). Moreover, THG, CS, and UM significantly reduced HA-induced growth of $\mathrm{CaOx}$ (33). It is worth emphasizing that OPN did not significantly affect $\mathrm{HA}$ induced nucleation and growth of $\mathrm{CaOx}$ (33), despite the fact that previous work has reported it to be a potent inhibitor of $\mathrm{CaOx}$ nucleation and growth $(50,51)$. More perplexing was the behavior of CS, which promoted CaOx nucleation but inhibited its growth (33).

It is now well-recognized that various urinary components, especially macromolecules, play an active role during crystallization in urine (49), yet only one previous study examined the possible epitaxial deposition of CaOx onto CaP seeds in urine (52). For a number of reasons, the results of that study are open 
to question. First, the authors did not mention the morphology of the CaP seeds, HA, or BR used, and their technique was very crude; it involved counting the number of precipitated particles with a Brand counting chamber and their identification by optical microscopy. Second, their assertion that CaP induced epitaxial deposition of $\mathrm{CaOx}$ was based simply on the observation that the number of precipitated particles (only some of which were identified) and $\mathrm{CaOx}$ dihydrate crystal increased in relation to rising concentration of soluble phosphate added to the urine. Third, they did not mention whether CaP seed crystals were overgrown by $\mathrm{CaOx}$ dihydratean event that would be expected had significant epitaxy occurred in their experiment. It is therefore unclear as to how or whether the presence of CaP nuclei in the precipitated $\mathrm{CaOx}$ crystals was demonstrated. In the present study, seed crystals of HA, BR, and $\mathrm{CaOx}$ were generated in undiluted human urine. After confirming their identities by X-ray powder diffraction analysis, they were added to undiluted human urine and precipitation of $\mathrm{CaOx}$ was induced by oxalate load. Analysis of ${ }^{14} \mathrm{C}$-oxalate data revealed that although seed crystals of $\mathrm{CaOx}$ promoted the mineral deposition by $23 \%$, HA and BR seeds had no significant affect in comparison with the control, to which no seeds were added. The degree of promotion caused by the $\mathrm{CaOx}$ seeds is of the same order as that produced by the commercial seed crystals of $\mathrm{CaOx}$ in another report using the same experimental system where ${ }^{14} \mathrm{C}$-oxalate deposition was promoted by $54 \%$ at 3 -fold higher final seed suspension concentration (53). Our data suggest that seed crystals of HA and BR do not promote $\mathrm{CaOx}$ deposition in undiluted urine and are therefore unlikely to act as nuclei for epitaxial deposition of $\mathrm{CaOx}$ to a physiologically significant degree in human urine in vivo.

It is remarkable that although solute deposition is a well-recognized mechanism of crystal enlargement, crystal aggregation is equally, if not, more important in stone formation. This is because it allows the formation of large, potentially dangerous particles within a short period of time and therefore increases the likelihood of particle retention within the renal collecting system. This supposition is supported by the observation that although both stone-formers and healthy subjects routinely pass $\mathrm{CaOx}$ crystals in their urine, it is only the former group where they are consistently aggregated into large clusters $(18,43)$. The results of the present study reveal that the average modal sizes of the particles deposited in the presence of seed crystals of HA and BR were not significantly different from those precipitated in the control sample to which no seed crystals were added. These observations are supported by the scanning electron microscopic findings.

Had epitaxy occurred to any significant degree in this study, one would have anticipated overgrowth of the seed crystals with $\mathrm{CaOx}$ (and possibly, therefore, morphology of pure $\mathrm{CaOx}$ ) or their envelopment by newly precipitated crystals of $\mathrm{CaOx}$, so that the seed crystals themselves would be hidden. Certainly, this was the case with $\mathrm{CaOx}$ seeds: scanning electron microscopic examination of the precipitated crystals at high magnification revealed that large aggregates of $\mathrm{CaOx}$ were formed in the presence of CaOx seeds, which themselves were not visible, presumably because they had been hidden by deposition of $\mathrm{CaOx}$ upon them. In contrast, BR and to a lesser extent HA seeds were clearly visible. Although some of them lay free on the filtration membrane, others were attached to the surface of the freshly precipitated $\mathrm{CaOx}$ crystals; some of these had been overgrown by the $\mathrm{CaOx}$ growth front and were evident as protuberances on the surface of the $\mathrm{CaOx}$ crystals. This suggests that after precipitation and growth of $\mathrm{CaOx}$ had occurred, the seed crystals attached themselves to the surfaces, and as crystal growth proceeded, the seeds became embedded within the CaOx crystal structure. The fact that this occurred in undiluted urine suggests that the process may also occur in vivo, where it could explain the occurrence of mixed phosphate/oxalate stones. Most important, these findings demonstrate that, even in the presence of adsorbed urinary macromolecules, crystals of HA and BR bind to the surface of $\mathrm{CaOx}$ crystals, not the other way around, as suggested by the epitaxy theory.

The results of our investigation are corroborated by the findings of Khan (54) and Burns and Finlayson (55). Whereas Khan (54) reported that, although CaP and $\mathrm{CaOx}$ crystals are closely associated in human and rat stones, they contain copious amounts of organic material, particularly on the interface between the crystals. This led him to conclude that epitaxial deposition of $\mathrm{CaOx}$ onto $\mathrm{CaP}$ is highly unlikely in vivo. The same conclusion was arrived at by Burns and Finlayson (55) who, using a rapidly mixed inorganic system of $\mathrm{CaOx}$ crystallization, found that fewer than $1 \%$ of HA seeds acted as nucleators.

It is interesting to note that critical appraisal of $\mathrm{X}$-ray crystallographic data, which are the mainstay of the epitaxy theory, in fact, undermine its veracity. This is mainly because $\mathrm{X}$-ray data provide only a theoretical comparison of the dimensions of prominent crystal faces, thereby allowing molecular analysis of crystal lattices in contact. Such analysis gives a large number of lattice matches between minerals commonly seen in stones at $<15 \%$ misfits (28), which reduces significantly at $<10 \%$ misfits, and approaches zero at $<5 \%$ misfits. On this basis, the most common mineral combination actually observed (HA mixed with CaOx monohydrate or dihydrate) would not be theoretically possible, and the relatively uncommon combination of $\mathrm{CaOx}$ monohydrate and cystine would be predicted to occur more frequently. This is because there are no lattice matches for $\mathrm{HA}$ and $\mathrm{CaOx}$, and one possible match between $\mathrm{CaOx}$ and cystine at misfits below $5 \%$. 
Furthermore, use of the molecular matching technique suggests that the separate mineral components in the $\mathrm{HA}-\mathrm{CaOx}$ monohydrate combination totally support each other's deposition at atomic level (31). However, according to results of in vitro studies, although HA supports heterogeneous nucleation of $\mathrm{CaOx}$, the converse is not true $(23,25)$.

Taken together, the results presented here demonstrate unambiguously that HA and BR seeds do not promote $\mathrm{CaOx}$ deposition to a physiologically significant degree in urine. Epitaxial induction of CaOx crystal nucleation by seed crystals of HA or $\mathrm{BR}$ is therefore unlikely to be a major factor contributing to stone formation.

\section{Acknowledgments}

The authors are indebted to Dr. A. Milnes, CSIRO, Division of Soils, Glen Osmond, South Australia, for performing the X-ray powder diffraction analyses of the seed crystals. Sincere thanks are also extended to Professor C.Y.C. Pak (University of Texas Southern Medical Center at Dallas, Dallas, Texas, USA) for providing the brushite seed crystals. This work was supported by grant 980366 from the National Health and Medical Research Council of Australia and grants from the Research Foundation of the Urological Society of Australasia, Flinders University of South Australia and Flinders 2000.

\section{References}

1. Sierakowski R, Finlayson B, Landes RR, Finlayson CD, Sierakowski N. (1978) The frequency of urolithiasis in hospital discharge diagnoses in the United States. Invest. Urol. 15: 438-441.

2. Robertson WG, Peacock M, Heyburn PJ, Hanes FA. (1980) Epidemiological risk factors in calcium stone disease. Scand. $J$. Urol. Nephrol. 53(suppl): 15-28.

3. Soucie JM, Thun MJ, Coates RJ, McClellan W, Austin H. (1994) Demographic and geographic variability of kidney stones in the United States. Kidney Int. 46: 893-899.

4. Robertson WG. (2001) The changing pattern of urolithiasis in the UK and its causes. In Kok DJ, Romijn HC, Verhagen PCMS, Verkoelen CF (eds). Eurolithiasis. Maastricht, The Netherlands: Shaker Publishing; 9-11.

5. Clark JY, Thompson IM, Optenberg SA. (1995) Economic impact of urolithiasis in the United States. J. Urol. 154: 2020-2024.

6. Prien EL, Prien EL Jr. (1968) Composition and structure of urinary stone. Am. J. Med. 45: 654-672.

7. Elliot JS. (1973) Structure and composition of urinary calculi. J. Urol. 109: 82-83.

8. Modlin M. (1967) The aetiology of renal stones: a new concept arising from studies in a stone-free population. Ann. $R$. Coll. Surg. Engl. (Lond.) 40: 155-178.

9. Boyce WH, King JS Jr. (1963) Present concepts concerning the origin of matrix and stones. Ann. N. Y. Acad. Sci. 104: 563-578.

10. Abraham PA, Smith CL. (1987) Evaluation of factors involved in calcium stone formation. Miner. Electrolyte Metab. 13: 201-208.

11. Royer L. (1928) Experimental research on parallel growth on mutual orientation of crystals of different species. Bull. Soc. Fr. Mineral 51: 7-159.

12. Lonsdale K. (1968) Epitaxy as a growth factor in urinary calculi and gallstones. Nature 217: 5658.

13. Lonsdale K. (1968) Human stones: limited studies give some details of composition, rates of growth, distribution, and possible causes. Science 159: 1199-1207.
14. Robertson WG, Peacock M, Nordin BEC. (1968) Activity products in stone-forming and non-stone-forming urine. Clin. Sci. 34: 579-594.

15. Pak CYC, Holt K. (1976) Nucleation and growth of brushite and calcium oxalate in urine of stone formers. Metabolism 25: 665-673.

16. Smith LH, Werness PG. (1983) Hydroxyapatite-the forgotten crystal in calcium urolithiasis. Trans. Am. Clin. Climatol. Assoc. 95: 183-190.

17. Berland Y, Boistelle R, Olmer M. (1990) Urinary supersaturation with respect to brushite in patients suffering from calcium oxalate lithiasis. Nephrol. Dial. Transplant. 5: 179-184.

18. Hallson PC, Rose GA. (1976) Crystalluria in normal subjects and in stone formers with and without thiazide and cellulose phosphate treatment. Br. J. Urol. 48: 515-524.

19. Werness PG, Wilson JWL, Smith LH. (1984) Hydroxyapatite and its role in calcium urolithiasis. In Ryall RL, Brockis JG, Marshall VR, Finlayson B (eds). Urinary Stones. Melbourne, London, New York: Churchill Livingstone; 273-277.

20. Tiselius HG. (1992) Recurrent stone formation in patients treated with ESWL. J. Stone Dis. 4: 152-157.

21. Tiselius HG, Larsson L. (1993) Calcium phosphate: an important crystal phase in patients with recurrent calcium stone formation? Urol. Res. 21: 175-180.

22. Pak CYC, Hayashi Y, Arnold LH. (1976) Heterogeneous nucleation with urate, calcium phosphate and calcium oxalate. Proc. Soc. Exp. Biol. Med. 153: 83-87.

23. Meyer JL, Bergert JH, Smith LH. (1975) Epitaxial relationships in urolithiasis: the calcium oxalate monohydratehydroxyapatite system. Clin. Sci. Mol. Med. 49: 369-374.

24. Meyer JL, Bergert JH, Smith LH. (1977) Epitaxial relationships in urolithiasis: the brushite-whewellite system. Clin. Sci. Mol. Med. 52: 143-148.

25. Koutsoukos PG, Sheehan ME, Nancollas GH. (1981) Epitaxial considerations in urinary stone formation. II. The oxalatephosphate system. Invest. Urol. 18: 358-363.

26. Berg C, Tiselius HG. (1989) The effects of citrate on hydroxyapatite induced calcium oxalate crystallization and on the formation of calcium phosphate crystals. Urol. Res. 17: 167-172.

27. Baumann JM, Ackermann D, Affolter B. (1989) The influence of hydroxyapatite and pyrophosphate on the formation product of calcium oxalate at different pHs. Urol. Res. 17: 153-155.

28. Mandel NS, Mandel GS. (1981) Epitaxis between stoneforming crystals at atomic level. In Smith LH, Robertson WG, Finlayson B (eds). Urolithiasis: Clinical and Basic Research. New York: Plenum; 469-480.

29. Ebrahimpour A, Perez L, Nancollas GH. (1991) Induced crystal growth of calcium oxalate monohydrate at hydroxyapatite surfaces. The influence of human serum albumin, citrate and magnesium. Langmuir 7: 577-583.

30. Achilles W, Jockel U, Schaper A, Burk B, Riedmiller H. (1995) In vitro formation of "urinary stones": generation of spherulites of calcium phosphate in gel and overgrowth with calcium oxalate using a new flow model of crystallization. Scanning Microsc. 9: 577-586.

31. Coe FL, Favus MJ, Pak CYC, Preminger GL. (1996) Kidney Stones: Medical and Surgical Management. Boston: Raven Press.

32. Hojgaard I, Fornander A-M, Nilsson M-A, Tiselius HG. (1998) The influence of hydroxyapatite seed on the crystallization induced by volume reduction of solutions with an ion composition corresponding to that in the distal tubule at different pH levels. Scand. J. Urol. Nephrol. 32: 311-319.

33. Beshensky AM, Wesson JA, Worcester EM, Snyder C, Kleinman JG. (2000) Urinary protein effects on heterogeneous nucleation of calcium oxalate on hydroxyapatite. In Rodgers AL, Hibbert BE, Hess B, Khan SR, Preminger GM (eds). Urolithiasis 2000. Cape Town, South Africa: University of Cape Town, Rondebosch; 116-118.

34. Stapleton AMF, Dawson CJ, Grover PK, et al. (1996) Further evidence linking urolithiasis and blood coagulation: urinary prothrombin fragment 1 is present in stone matrix. Kidney Int. 49: $880-888$. 
35. Nishio S, Hatanaka M, Takeda H, et al. (2000) Calcium phosphate crystal-associated proteins: alpha 2-HS-glycoprotein, prothrombin Fl, and osteopontin. Mol. Urol. 4: 383-389.

36. Doyle IR, Ryall RL, Marshall VR. (1991) Inclusion of proteins into calcium oxalate crystals precipitated from human urine: a highly selective phenomenon. Clin. Chem. 37: 15891594.

37. Self PG, Pickering JG, Raven MD, Riley GG, Rosser H, Stone PA. (1987) Procedures for the control and manipulation of $\mathrm{X}$-ray powder diffraction data from remote locations based on a Phillips PW1710 diffraction control system. I. Automatic control of the diffractometer-user's manual. Glen Osmond, South Australia: CSIRO Division of Soils Technical Memo No. 75/1987.

38. Raven MD, Self PG. (1987) Procedures for the control and manipulation of $\mathrm{X}$-ray powder diffraction data from remote locations based on a Phillips PW1710 diffraction control system. II. Handling procedures for data from the PW1710. Version 1.00. Glen Osmond, South Australia: CSIRO Division of Soils Technical Memo No. 91/1987.

39. Doyle IR, Ryall RL, Marshall VR. (1989) The effect of lowspeed centrifugation and millipore filtration on the urinary protein content. In Walker VR, Sutton RAL, Cameron ECB, Pak CYC, Robertson WG (eds). Urolithiasis. New York: Plenum; 593-594.

40. Ryall RL, Harnett RM, Hibberd CM, Edyvane KA, Marshall VR. (1991) Effects of chondroitin sulphate, human serum albumin and Tamm-Horsfall mucoprotein on calcium oxalate crystallization in undiluted human urine. Urol. Res. 19: 181-188.

41. National Institute of Health Consensus Development Conference Statement. (1989) Prevention and treatment of kidney stones. J. Urol. 141: 804-808.

42. Ackermann D, Baumann JM. (1987) Chemical factors governing the state of saturation towards brushite and whewellite in urine of calcium stone formers. Urol. Res. 15: 63-65.

43. Robertson WG, Peacock M, Nordin BEC. (1969) Calcium crystalluria in recurrent renal-stone formers. Lancet 5: 21-24.
44. Strates BS, Neuman WF, Levinskas GJ. (1957) The solubility of bone mineral. II. Precipitation of near neutral solutions of calcium and phosphate. J. Phys. Chem. 61: 279-282.

45. Pak CYC, Eanes ED, Ruskin B. (1971) Spontaneous precipitation of brushite in urine: evidence that brushite is the nidus of renal stones originating as calcium phosphate. Proc. Natl. Acad. Sci. U.S.A. 68: 1456-1460.

46. Pak CYC. (1969) Physicochemical basis for formation of renal stones of calcium phosphate origin: calculation of the degree of saturation of urine with respect to brushite. J. Clin. Invest. 48: 1914-1922.

47. Pak CYC. (1981) Potential etiological role for brushite in the formation of calcium (renal) stones. J. Crystal Growth 53: 202-208.

48. Pak CYC, Skinner HCW. (1968) Ionic interaction with bone mineral. IV. Varying affinity of synthetic calcium phosphates for $\mathrm{Ca}^{2+}$. Biochem. Biophys. Acta 165: 274-282.

49. Ryall RL. (1996) Glycosaminoglycans, proteins, and stone formation: adult themes and child's play. Pediatr. Nephrol. 10: 656-666.

50. Worcester EM, Blumenthal SS, Beshensky AM, Lewand DL. (1992) The calcium oxalate growth inhibitor protein produced by mouse kidney cortical cells in culture is osteopontin. J. Bone Miner. Res. 7: 1029-1036.

51. Worcester EM, Beshensky AM. (1995) Osteopontin inhibits nucleation of calcium oxalate crystals. Ann. N. Y. Acad. Sci. 760: 375-377.

52. Grases F, Conte A, Gil JJ. (1988) Simple method for the study of heterogeneous nucleation in calcium oxalate urolithiasis. Br. J. Urol. 61: 468-473.

53. Grover PK, Ryall RL. (1997) Effect of seed crystals of uric acid and monosodium urate on the crystallization of calcium oxalate in undiluted human urine in vitro. Clin. Sci. 92: 205-213.

54. Khan SR. (1997) Calcium phosphate/calcium oxalate crystal association in urinary stones: implications for heterogeneous nucleation of calcium oxalate. J. Urol. 157: 376-383.

55. Burns JR, Finlayson B. (1980) The effect of seed crystals on calcium oxalate nucleation. Invest. Urol. 18: 133-136. 